\title{
Measuring resilience in energy systems: Insights from a range of disciplines
}

\author{
Lynette Molyneaux ${ }^{1 a}$, Colin Brown ${ }^{b}$, Liam Wagnera, John Foster ${ }^{a}$ \\ a. Energy Economics and Management Group, School of Economics, University of Queensland, Australia \\ b. School of Agriculture and Food Sciences, University of Queensland, Australia
}

Keywords: Resilience, Sustainable Energy, Energy Security

\begin{abstract}
Economic stability is dependent on the effective functioning and resilience of energy systems. Resilience is a term used across all research disciplines and in everyday discourse. As a concept it purports to serve as a useful indicator of sustainability and robustness, but it has proved difficult to measure. Ecological resilience, psychological resilience, risk management and energy security are all fields of research in which measures of the ability to respond to the unexpected are sought. The goal is to build adaptive capacity but quite different methods have been developed to achieve this end. Research on energy security, in particular, has focused on the security of oil supplies, not resilience or the adaptive capacity of the energy system or the role that renewable energy plays in building such capacity. This paper discusses how different disciplines seek to measure and build resilience and explores its connection with the state or quality of a system's adaptive capacity. When the parameters of redundancy and diversity are present, resilience is enhanced. For this reason, in energy systems we must understand the size and scope of the key parameters required to facilitate the development of adaptive capacity and to build resilience that can enhance economic stability.
\end{abstract}

\section{Contents}

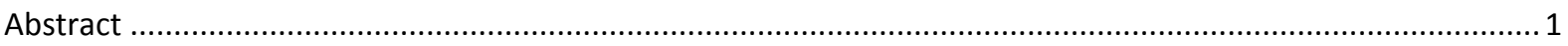

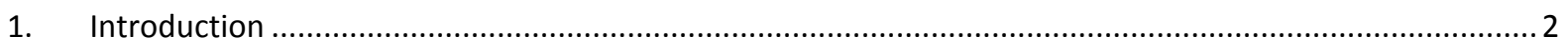

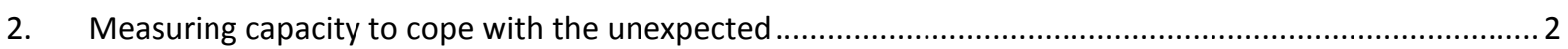

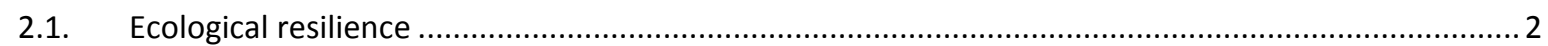

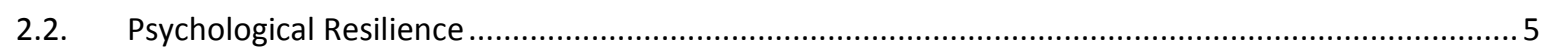

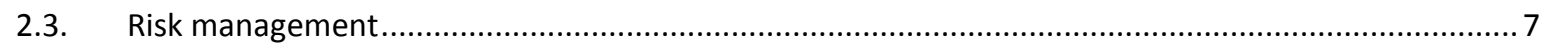

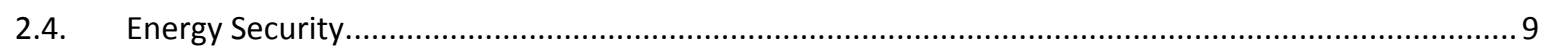

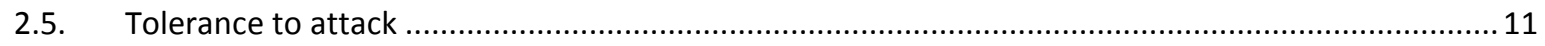

2.6. Towards common themes and factors in the measurement of resilience .................................. 12

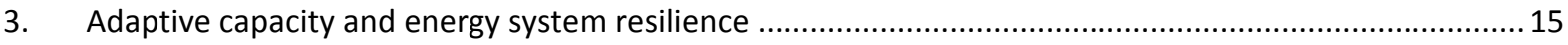

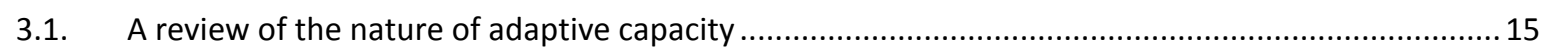

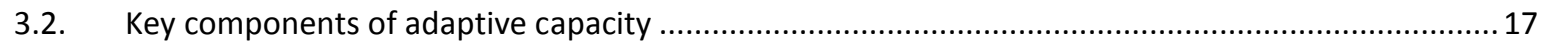

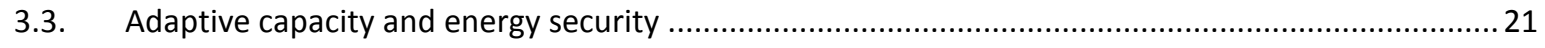

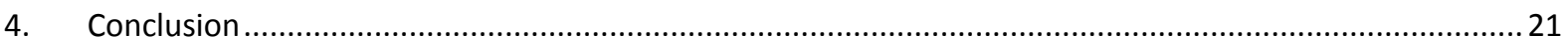

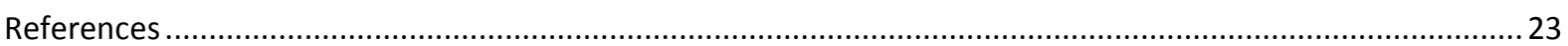

\footnotetext{
${ }^{1}$ Corresponding author. Address: Energy Economics and Management Group, School of Economics, University of Queensland, St Lucia, Brisbane, 4072, Australia. Tel: +61 733467059

Email addresses: I.molyneaux@uq.edu.au, j.foster@uq.edu.au, I.wagner@uq.edu.au, colin.brown@uq.edu.au
} 


\section{Introduction}

Resilience is a term widely used in the public discourse as well as in research. It is generally understood to mean the ability to cope with misfortune, shock and the unexpected. However, less attention has been devoted to the measurement of resilience and an understanding of the underlying parameters required for resilience. Several disciplines have attempted to measure the capacity to cope with the unexpected but are there commonalities in the definition and measurement of resilience?

If there are commonalities in the research into measuring resilience, then the resultant parameters might be applied to energy systems to determine their ability to adapt and respond to change. Oil became a key strategic weapon in the First and Second World Wars by enhancing the ability to surprise the opponent [1], but the heavy reliance on cheap oil to build post war economies played a part in inducing the economic inertia that followed the 1970 s oil crises [2, 3]. The history of oil use highlights the crucial role that the supply of affordable energy plays in responding to attack and facilitating stable economies. However, oil is not the only source of fuel for energy systems. Renewable sources of energy, such as hydroelectricity, have also played a part in energy systems' ability to respond to the unexpected. It is therefore important to identify the components that have impacted on the adaptive capacity and resilience of energy systems when faced with energy shocks.

In this paper we discuss the definitions and measurement of resilience as proposed in different disciplines. Research on resilience started in ecology and psychology but other disciplines such as risk management and energy security have also focused on the ability to cope with the unexpected. Protection against attack, both military and institutional, is important for societal stability, so the ability to tolerate attack is also pertinent. By virtue of the wide-ranging disciplines involved, the review is far from exhaustive, but does include discussion of the key themes dealing with the capacity to respond to surprise.

The discussion proceeds as follows. Section 2 summarises the definitions and measurements proposed for ecological resilience, psychological resilience, risk management, energy security, and tolerance to attack. A discussion of the common themes in resilience and the capacity to cope with the unexpected in Section 3 identifies the key parameters required for resilience in energy systems. Section 4 draws conclusions with respect to the measurement of resilience in energy systems.

\section{Measuring capacity to cope with the unexpected}

\subsection{Ecological resilience}




\subsubsection{Definitions of ecological resilience}

There have been 2 definitions of ecological resilience. Pimm proposed that resilience is the rate at which a system returns to equilibrium following a disturbance [4]. Holling proposed resilience as a measure of a system's ability to absorb and accommodate future events in whatever unexpected form they may take [5].

Holling drew a distinction between the concepts of resilience and stability. He defined stability as the ability of a system to return to an equilibrium state after a temporary disturbance; the more rapidly it returned and the less it fluctuated, the more stable it would be. In contrast to Pimm, Holling observed that equilibrium and stability provided little insight into the transient behaviour of systems [5]. Based on observations of ecological fluctuations over long periods, he found that systems can exhibit evidence of complex relationships between resilience and stability and that systems with a highly unstable community may still be resilient. As a result, Holling defined resilience as being distinct from stability, as a measure of the system's ability to absorb disruption, maintain self-

organisation, and avoid breaching thresholds and irreversible change. This entailed a shift away from attempting to calculate optimal equilibrium points, towards analysing a system's capacity to persist or be resilient [5] and stressing that the source and role of change in systems must be understood [6]. Thus, Holling's view of resilience involved an evolutionary understanding of a system's response to any profound exogenous change.

The Holling school further refined the definition of resilience in relation to engineering resilience, that is the rate of return to a steady state within a stable domain after a perturbation, generally evidenced in systems that function locally around small changes (the view of resilience as held by Pimm). This contrasts with ecological resilience, or the ability of a system to reorganise through unstable domains to a new steady state using different processes and structures. Such systems are seen as functioning regionally and experience significant levels of change (the view of resilience as held by Holling)[7].

Thus, variability is an essential ingredient of ecosystem survival: suppressing variability leads to compromised systems and system responses [6]. Adaptation to exogenous change requires a system that can maintain function, self-organise, and learn [6]. Evolving systems show evidence not of a tendency toward some stable or equilibrium condition but of an adaptive cycle: rapid growth and exploitation; conservation or growing brittleness; collapse, readjustment or release (creative destruction); and re-organisation for renewal [8].

'Keystone' species and processes show what the organisational structure, including the role played by diversity and overlap (or redundancy), must be to have ecosystem resilience [9, 10].

\subsubsection{Measuring ecological resilience}

Underpinning ecological stability theory are the Lotka-Volterra differential equations, particularly the 'predator-prey model', which were adapted to describe the dynamics of species interactions, patterns of oscillation, and population limits and thresholds. These 
models did not provide predictions consistent with ecosystem behaviour such as multiple stable and transient states, the ability to shift from one domain of attraction to another, substitutability between and amongst elements of the ecosystem, and unpredictable responses to random unexpected events. Where economic factors were included, discounting was used as part of the analysis, which minimised long-term consequences $[5,6$, 11]. The attempt at establishing equilibrium in an ecosystem was encouraged by a requirement to calculate maximum yields for socio-economic benefit rather than to accurately predict ecosystem behaviour $[12,13]$.

As an alternative Perrings suggested analysing the transition dynamics of stochastic multiple equilibrium systems using a Markov process to measure resilience as an evolutionary process [14]. Using transition probabilities derived from historical performance, simple Markov models have shown prediction accuracy for a limited number of parameters [15, 16]. However, predictive capabilities for complex, dynamic systems are always limited by lack of knowledge and data on a greater range of relevant parameters [15].

Berkes and others sought to measure resilience in a different way by assessing the ability of complex adaptive systems to respond to disturbances through adaptive relationships, learning and self-organisation. This requires attention to feedbacks, nonlinearity, unpredictability and cyclical behaviour in response to disturbances. In general, case studies have been used to highlight the impact of socio-economic behaviour [17]. Agent-based models have been of interest because they can capture instability and exhibit cyclic or chaotic dynamics reminiscent of what is observed in socio-ecological systems [18]. Predictions, derived from case studies and agent based models, have been used to assess the outcomes of different policy approaches. With such findings, suggestions have been made as to how the stability of the ecosystem could be improved through the management of target variables[19].

In some studies, Cost-Benefit analysis has been used to assess trade-offs between the benefits of developing natural resources and the resulting consequences, versus not developing these resources [20]. The focus of such studies has been primarily to support ecosystem managers seeking to quantify the social benefit derived from a natural system at a level sufficient to ensure the continued survival or health of that system. Thus, measurement of resilience is implicit rather than explicit. Because uncertainty looms large in such contexts, conclusions from such analyses have often been challenged, especially with respect to valuing ecosystem functions and services [18]. The importance of biodiversity in ecosystem resilience has been discussed at length. Statistical models using multiple regression techniques have shown that biodiversity points to greater stability although such studies have used a mixture of terms to describe positive outcomes [21-23]. So both the results and methods have been questioned [24]. Carpenter et al also used experimentation and regression analysis to calculate resilience in terms of a basin of attraction (the area representing system control on structure and function). They concluded that slow variables 
and their interaction with fast variables are important for determining resilience [18]. Indeed in earlier discussions on evolution, flexibility or homeostasis was thought to result from the interaction of slow and fast variables [25]. Carpenter et al's findings show that slow variables represent the underlying structure of the system and fast variables reveal the dynamics of the system structure, constructs borrowed from evolutionary theory and the analysis of homeostasis, to measure resilience.

Ulanowicz used information theory to develop a quantitative theory of ecosystem succession in response to observations that proliferation and evolution are based on positive feedbacks [26]. As autocatalytic configurations (positive feedbacks) tend to shift a system toward greater levels of performance, he represented the effect of organisational structure in an ecosystem using Boltzmann's measure of disorder to calculate what he refered to as indeterminacy, as a measure of 'how surprised the observer will be when [an event] occurs' [26, P309]. Indeterminacy, or surprise, will be constrained by levels of certainty as a result of organisation inherent in the system, which he calls ascendancy. System ascendancy is disturbed by chance perturbations, and will increase and decrease over time depending on the freedom the system has to respond. This residual freedom is enhanced by diverse flows that can occur in the system. The amount by which system capacity exceeds ascendancy, can be considered to be system 'overhead', redundancy, or as some have suggested, resilience [27]), which shows the potential of the system to recover from shocks and maintain system integrity. Ulanowicz suggested network analysis as a modelling technique, in conjunction with the construct of system ascendancy (the size and organisation structure of the network), to provide a top-down understanding of the functioning of a complex ecosystem [28]. He postulated that the capacity of the system for sustainable development is a function of its inherent organisation, or structure, plus its inherent disorder encapsulated in the concepts of diversity and redundancy[29].

Other tools for the evaluation of sustainable development (which implies resilience) have taken the form of: simple measures representing a state or performance indicator, with multiple indicators aggregated into indices to enable tracking of long-term trends; or integrated assessment such as multi-criteria analysis that combine natural and social aspects .

\subsection{Psychological Resilience}

\subsubsection{Definitions of psychological resilience}

Redl defined 'ego resilience' as the capacity of an ego to withstand pressure. By implication, this included the ability to rebound from temporary collapse without assistance. He sought to explore the demarcation between the ego that loses control and "the ego that courageously maintains an unpopular or misunderstood stance" [30, P98].

In Murphy's research she found that different individuals mustered a different range of resources to deal with life stress. She saw resilience as an evaluative concept like 
competence and adaptation rather than a single trait. In a shift away from the dictionary definition that resilience is about a return to the norm, she advanced the notion of preparing for the future, with "the resilient child is oriented toward the future, is living ahead, with hope" [31, P101].

Cohler looked to Anthony's promotion of the importance of adversity to develop strength, cohesion and creativity [32] to formulate his definition of resilience. He saw it as a response to adversity and "the ability to cope with unexpected, eruptive events, pressures imposed by strains of everyday life, and lack of available social supports in dealing with expected life transitions" [33, P404].

Vaillant suggested resilience was a "clear pattern of recovery, restoration and gradual mastery" over long time frames [34, P311] whereas Masten defined resilience as the "phenomena characterised by good outcomes in spite of serious threats to adaption or development "[35, P228]. Conversely, Ungar described resilience "as a set of behaviours over time that depends on the opportunities that are available and accessible to individuals, their families and communities" [36, P3] and that resilience results from the capacity created through the individual's environment, a physical and social ecology, to provide the scaffolding for human development.

Despite the difference in the definitions, a common thread is the ability of the individual to adapt to life's adversities.

\subsubsection{Measurement of Psychological resilience}

Measuring psychological resilience has been complicated because of its conception as " $a$ superordinate construct subsuming two distinct dimensions - significant adversity and positive adaptation - and thus is never directly measured, but is indirectly inferred based on evidence of the two subsumed constructs"[37, P742].

Werner's longitudinal study of a cohort on Kauai island, Hawaii used discriminant function analysis with canonical correlation coefficients to examine the pattern of weights of sets of stressors that predict poor versus good adaptation and latent variable path analysis to show how protective factors, within the individual and provided by outside sources of support, linked across time to enable prediction of the quality of adaptation in later life. The protective processes that were associated with positive adaptation in later life included maternal competence (including age and schooling), autonomy and social maturity (including IQ and social orientation), scholastic competence and realistic educational and vocational plans, emotional support, and health. The protective factors identified were similar to those identified in other longitudinal studies and showed evidence of providing a buffer against adversity. Werner considered resilience to be the result of protective mechanisms that allow the individual to deal with adversity [38].

There are a few key themes that run through the Kauai island study that are discussed, namely education and interpersonal relationships. Education underlies many of the 
protective factors identified from maternal education as an element of maternal competence, to attitudes to school and education being part of self-efficacy. Positive interpersonal relationships also appear to underpin the positive forces of maternal competence, self-efficacy and emotional support.

Research continues, now seeking understanding of the importance of environmental factors for resilience in addition to the latent capacity of an individual to respond to adversity. In this research, coping capacity is seen to be enhanced as a result of the opportunities presented through the individual's family, neighbourhood and community to facilitate the individual's capacity to respond effectively. Resilience, as a set of observable behaviours (including self-esteem, attachment, efficacy, peer relations and financial capacity) associated with adaptation to adversity, is measured using a variety of statistical techniques including regression analysis, factor analysis, multivariate analysis, principal component analysis and structural equation modelling $[36,39]$. There have been many protective factors identified as important to different varieties of coping capacity but little analysis on core protective factors and specific personal and social characteristics across multiple groups and studies.

Discussion about the relationship between resilience and high levels of social support and low financial hardship would tend to support the view that having the resources to pursue options does indeed increase the ability to respond to the unexpected. Also, studies show that keeping adolescents in protective environments like school helps buffer them against being subsumed by risky environments. Thus options and capacity to negotiate risks provide scaffolding in the development of coping strategies [36, 39] .

\subsection{Risk management}

\subsubsection{Definitions of Risk and Risk Management}

Oxford Dictionaries define risk as "a situation involving exposure to danger", Macquarie Dictionary as "the state of being open to the chance of injury or loss". Notably, the emphasis is on danger or loss, not uncertainty.

Knight discussed risk in the context of contribution to profit. He separated the definition of risk, as calculable, from uncertainty, as incalculable. Thus, risk management, in Knight's perspective would be about analysing the calculable, but employing experts to provide good judgement about inherent uncertainties [40].

Britain's Royal Society published on the subject of risk in 1983 in a report entitled Risk Assessment. This report distinguished between 'objective' risk, calculable from data (and what Knight would define as risk rather than uncertainty), as opposed to, 'perceived' risk, a subjective response to danger. It sought only to define objective risk as "the probability that a particular adverse event occurs during a stated period of time, or results from a particular challenge." [41] and did not address uncertainty as identified by Knight. In 1993, the Royal Society again published on the subject of risk in Risk: analysis, assessment, 
management and introduced discussion by social scientists that risk is culturally constructed and conditional; that "the adverse nature of particular events and their probability are inherently subjective" [41, P9]. Aligned with this view, Adams defines risk as an interactive phenomenon that defies measurement because of the significant levels of uncertainty over the future coupled with varying responses to different views of risk [41].

Bernstein's book on risk states that "Risk derives from the early Italian risicare which means "to dare". In this sense risk is a choice not a fate. The actions that we dare to take, which depend on how free we are to make choices, are what the story of risk is all about" $[42, \mathrm{P} 8]$.

In the safety management discourse "Resilience Engineering" is proposed to avoid accidents and is defined as establishing a practise of analysing, measuring and monitoring a system's operation, responding with improvements and by so doing provide "the ability to create foresight - to anticipate the changing shape of risk, before failure and harm occurs." [43, P6]

Many definitions of risk highlight the opportunity for loss rather than choice. This supports the views of Kahneman and Tversky that human beings have a great aversion to loss [44]. The innate problem that uncertainty presents is that human beings can only judge the future according to the past, when the future is not necessarily governed by the rules of the past.

\subsubsection{Measuring risk}

Probability theory is the principal tool for measuring risks. The Law of Large Numbers and the Central Limit Theorem have provided the mathematical structure for professional risk takers to offer a service that provides surety for the individual and returns a profit for the risk manager [42]. Thus insurance is offered on the basis of information gathered about the insured, matched to historical statistical evidence of similar characteristics. Whilst there is no certainty with respect to individual outcomes, the umbrella of the large numbers involved enables individuals to be assured of certainty in times of uncertainty, and insurers to be assured of certainty in numbers. Actuarial calculations for insurance measure risk and provide a mechanism for risk management.

Portfolio theory, developed for the investment community, uses historical variance to the mean of returns as a measure of risk for each security. The theory adds historical calculations of covariance between securities to calculate the selection of an optimal investment portfolio for a given amount of risk or expected variance [45]. Returns that are independent of each other reduce risk, potentially increasing expected return. This has led to the general acceptance that diversity is the most significant contributor to risk management in investment strategy $[42,46]$. The methodology is highly dependent on historical data, to infer what might be the best options for an uncertain future. Portfolio theory has also been applied at a system level, to ecosystem based fisheries management 
and risk management in financial systems, to shift the management of risk away from analysis of individual species or product risk to analysis of systemic risk. This assesses excessive homogeneity in behaviour which results in brittleness and cascading collapse when confronted with large perturbations [47].

"Resilience Engineering" proposes that complex systems must not only cope with known variations in the system but that they must adapt to unknown variations in the system as it changes over time. In the pursuit of safety they discuss the requirement not only for efficiency, but thoroughness as well and that, without thoroughness, the risk of accident and general failure increases significantly. Thus, resilience is measured as system fault tolerance with monitoring triggering adjustments to enhance adaptation [43].

\subsection{Energy Security}

\subsubsection{Definitions of energy security}

There are many definitions of energy security but in the main they boil down to the energy system's ability to supply energy to meet demand at an affordable price $[48,49]$.

Furthermore they have focussed on limiting the chance of, and consequences of, supply disruptions of oil [50]. Extensions of the concept have included that uninterrupted supply of energy is critical to the functioning of an economy [51] and that new challenges to deal with environmental requirements, technology lock-in, fluctuations in demand, socio-economic concerns and military risks also have a role to play in defining energy security [50]. Inversely, energy insecurity has been defined as the loss of welfare that results from a change in price or availability of energy $[52,53]$. Without a clear definition, energy security may become a catch-phrase for justifying policy that may not be supported by economic reasoning [49].

Whilst some propose narrowing down the concept to energy supply continuity rather than a broader definition including economic efficiency and sustainability issues [49], many others suggest that energy security must include several key elements. The first is the availability of energy for use in an economy. Due to potentially large spatial distances between the location of reserves and demand centres, accessibility is the second element that plays a very important role in security of supply. For sustainability purposes, it is important to have acceptability as a precept for societal buy-in to address environmental consequences. Finally, to ensure the smooth running of the supply-demand system and the implications for economic performance, it is important for the end-product to be affordable [51].

\subsubsection{Measurement of energy security}

Much of the measurement of energy security has taken the form of indicators either calculated on their own or coupled with other indicators. They include measures such as resource estimates, reserve to production ratios, diversity indices, import dependence, political stability, energy price, mean variance portfolio theory, carbon intensity, market liquidity and demand-side indicators including energy-intensity and oil-use per capita [51]. Generally these indicators are used for comparative purposes, either to show trends, 
historical and projected, or to indicate levels of difference in countries perceived as having greater or lesser levels of energy security. Aggregating multiple elements within one indicator reduces transparency of the underlying dynamics, masking the trade-off between comprehensiveness, transparency and subjectivity which makes it impossible to assess energy security [51]. Aggregated indices have become popular but are swamped with an ever-growing number of metrics [54-56].

It is broadly accepted that practical measures of diversification are an important strategy to offset the risk associated with being too dependent on any one source. Diversity measurements in energy supply have been discussed in detail [52, 53, 57-61]. In many cases analyses tend to focus on projections rather than on establishing the robustness of measurements based on historical outcomes.

Mean-variance analysis seeks to use portfolio theory to calculate the potential for reducing risk in a generation portfolio by increasing low-risk or risk-free options [62, 63]. However, there is little attempt to prove the efficacy of mean-variance portfolio analysis using historic, empirical data. So the analyses focus on the attractiveness or otherwise of electricity generation projections including risk-free energy options like renewable energy [64].

Bohi et al analysed the body of research on models used to provide evidence of, and size of, externalities associated with market power, inflation, balance of payments impacts, investment, and productivity impacts as a result of the 1970s and early 1980s oil price volatility [53]. Wealth-maximisation models based on resource owners choosing prices that maximise net present value of profit show limited ability to predict the outcomes experienced in the 1970s [65]. In an analysis of marginal costs of oil production, it was found that the oil price spikes after 1973 could not be explained by changes in scarcity [66] and Adelman concluded that a "Clumsy Cartel" had caused market instability which resulted in cumulative and self-reinforcing price trajectories [67]. Alternative hypotheses suggest that the unpredictability of the oil price from 1973 to 1986 was more likely to have been as a result of panic buying and inventory stocking than predictable, rational economic behaviour [53]. Macroeconomists were sceptical that a resource that accounts for only $3 \%$ of GDP would be capable of inducing such large GDP losses in the US [2]. Bohi et al concluded that the economic woes of the 1970s and 1980s were more to do with macroeconomic policy to restrain inflation than energy prices per se. They asserted that weak or non-existent evidence of impacts makes it impossible to measure energy security. In the face of this uncertainty, they suggested that investment in diversification and research and development to improve energy efficiency, as the most appropriate energy policy actions to increase energy security [53].

Others suggest that Bohi et al's discussions focus on economic models that are based on subjective assumptions [52]. The models assume unrealistic assumptions such as perfect competition, fail to recognise the complicated interactions that exist in the modern 
economy, do not account for the lack of available information about geopolitical conditions and oil market risks, do not allow for the asymmetric response experienced by economies to price disruptions, and consequently do not connect with real world experience $[68,69]$. Hamilton finds that specialisation of labour and capital amplified the effects of historical oil price shocks and introduced non-linearities which support his finding that 10 out of the 11 post war US recessions have been preceded by a sharp increase in the price of oil [3]. Many researchers have concluded that recessionary movements of GDP are considered to be attributable to oil price shocks rather than the consequences of monetary policy [2].

Precise measurement of what constitutes energy security remains elusive. As a result, prescriptions for government intervention to secure energy security have sought to encourage energy substitution, efficiency, the establishment of reserves as buffers against future sharp oil price increases, and institutional structures to co-ordinate responses to crises and provide information about risks and dependencies [53].

\subsection{Tolerance to attack}

\subsubsection{Definition of Tolerance to attack}

The UK's Ministry of Defence publishes the British Defence Doctrine which sets out the broad philosophy and principles employed in the operation of the Armed Forces to secure outcomes which are politically favourable. The Defence Doctrine outlines principles of warfare as: selection, maintenance and support of an aim; co-operation; concentration of force; economy of resource use; flexibility; maintaining morale; taking offensive action; security; sustainability; and the use of and ability to respond to surprise, as a key psychological feature of warfare [70]. Thus winning wars is as much about the organisational structure of the Armed Forces as it is about the leadership of key individuals and their creativity in an environment of chaos and surprise.

Organisational structure, however, is about that nature and extent of connections [71]. It defines the structure of transport through a system, in the form of data, pulses, oscillations, energy, prices or relationships. Tolerance to attack is about the security of that flow in the event of disruption. Different arrangements of connection provide different levels of tolerance or defence.

\subsubsection{Measuring Tolerance to attack}

Ancient history is littered with evidence of societies that have flourished and then collapsed. Many suggest that the collapse is in response to resource and energy exhaustion [72], whilst others suggest that the collapse was a process of "change from one structurally stable level to another" [73, P38]. Tainter postulates that what drives this shift away from a stable structure is the increasing costs of society's organisation which his studies indicate become too complex and require too much energy to maintain. Current dominant armies follow principles of warfare in responding to attack - a framework for adaptive capacity - the 
ability to respond to surprise. However, there are no metrics to indicate the capacity of armies to tolerate an attack.

For this reason, it is logical to turn to studies that have analysed structure to understand the part it plays in adaptive capacity and resilience. Much of the research into structure starts with Stanley Milgram's experiments to measure connectedness in society, what came to be known as "The Small World Problem", that is the average number of connections that exist between any two individuals in the United States [74, 75]. However, research into biological oscillations and the role that phase singularities (that is, states that display an organising role in rhythmic return) play in oscillations demonstrates a possible principle of organisation [76]. Others demonstrate the potential for disorder to provide a mechanism for selforganisation and control in chaotic arrays by creating sub-populations that frequency-lock to one parameter [77]. Watts and Strogatz modelled networks of coupled dynamical systems of neural networks, spatial games, and other self-organising systems to understand connection topology. They advanced the concept of introducing increasing levels of disorder to analyse how a Small World Network, i.e., a network characterised by small path-lengths but sparse connections, might respond to a disturbance. They found that introducing a few long-range edges into a highly clustered large world network, created short-cuts that had a highly non-linear effect on path-length, contracting the distance between the vertices that it connected as well as the neighbourhoods that it connected. In contrast, removing an edge from a clustered neighbourhood to make a short-cut, had only a linear effect on the clustering, making the impact of a transition to a Small World Network nearly unnoticeable. The significance of their findings, amongst other things, indicated that the spread of infectious diseases through a Small World Network, would be faster than through a highly clustered large world network, because of the effectiveness of the short-cuts [78]. Thus, whilst a Small World Network can produce a desirable result in terms of efficiency gains, it also produces an undesirable result in terms of efficient transport of shocks.

Albert et al found that the robustness of a complex system can be attributed to the redundant interconnection within its functional structure but they found that the structure and dispersal of the interconnections determines the level of tolerance to errors as opposed to tolerance to attacks [79]. Where errors occur randomly, scale-free networks (that is, networks that have inhomogeneous connectivity with a few highly connected nodes that facilitate efficiency in transport) show greater levels of tolerance to errors than do exponential networks (that is, networks that are homogeneously connected with each node having a similar number of connections). However, if the network were to face a targeted attack on one or more of the highly connected nodes, then the reverse would be true.

\subsection{Towards common themes and factors in the measurement of resilience}

The search for models that can help predict, mathematically, the ability of an ecosystem to rebound from stochastic shocks has stretched across several decades. Proof of the efficacy of the models proposed has been thwarted by a lack of knowledge about ecosystem 
function and data. As Stuart Pimm points out, "The problems that ecologists face are so large: how do we contemplate processes that last longer than our research careers and that involve more species than we can count, over areas far too large for conventional experiments?" [80, Pxi]. Much of the research into ecological resilience has focused on showing the role that diversity plays in resilience $[9,22,23,81,82]$. Redundancy as an element of resilience has also been discussed [7, 23, 24, 29] although there is little empirical evidence to support its relevance. System capacity to respond has also been a favoured topic $[6,8]$, with measurement of slow and fast variables proposed as suitable metrics for resilience. The crucial roles of structure, diversity and redundancy in adaptation have been referenced as individual elements but seldom as the cumulative componentry required for adaptive capacity of ecological resilience.

Measurement of psychological resilience shows a pragmatic acceptance of the inevitability of life's ups and downs, and that adversity may deliver benefits; a view supported by quotes like Francis Bacons" "He knows not his own strength that hath not met adversity" and "Adversity best discovers virtue" and Shakespeare's "Sweet are the uses of adversity", in part "ugly and venomous", but also "a precious jewel" [32, P10]. Withstanding or being able to adapt to shocks can deliver stronger outcomes for individuals, so attempting to minimise the extent of a shock is perhaps in some way diminishing the benefit that could be gained by learning about shock. Psychological resilience research points to protective factors such as latent ability, education, social support and financial capacity all contributing to the coping capacity and positive development of the individual and that increasing options for individuals delivers benefits $[83,84]$. These protective factors are not dissimilar to the function that diversity, spare capacity and structure play in adaptive capacity as espoused in ecological resilience. Consider the benefit of education as a predictor of better outcomes: education delivers more options for individuals and greater potential earnings for families, such that individuals and families with higher levels of education find themselves with alternatives and can make better decisions rather than be dependent on only one option which may not be beneficial. Having more options allows the accumulation of assets which in turn provides a safety net for when things go wrong. Therefore key protective factors are the structural foundation for coping capacity and the similarities between these protective factors and the componentry of adaptive capacity in ecological resilience may be masked by the different terminology used by the different disciplines.

The measurement of risk has developed to counteract individual exposure to loss through the protection of the group. It is the diversity and spare capacity or redundancy contained in large numbers that underpins risk management. There is also a certain pragmatism around discussions of risk and risk management which accept that mathematical models will be insufficient for absolute accuracy and that decision making reflects both a statistical component as well as an element of, mathematically incalculable, judgment $[40,45]$. In the management of safety it is accepted that perfectly constructed models are unable to anticipate the full spectrum of unpredictable challenges and that monitoring and 
management to uncover and respond to faults and 'near misses' need to be overlaid on system structure to facilitate adaptation and resilience [43]. Although implicit, the concepts of diversity, redundancy and system management underpin the adaptive capacity provided by risk management.

Measurement of energy security has focused on oil security rather than a comprehensive view of the entire energy system, although some discussion has sought to quantify benefits from diversification in energy sources through the deployment of renewable energy [85, 86]. Measuring vulnerability to energy shocks has been based on the age-old stability heuristics, as advanced by ecologists, of diversity, spare capacity, system structure and monitoring. The International Energy Agency (IEA) was established to oversee the global monitoring and advisory role for energy security. The US pursued regulation to encourage diversity in the source of fuel for power generation, established the Strategic Petroleum Reserve, and regulated efficiency levels in vehicle fuel use. Yergin summarises requirements for energy security as "Diversification will remain the fundamental starting principle of energy security" in a framework of energy security componentry which includes reserves (which he terms resilience), efficiency (which he refers to as integration to provide stability), and information which helps in the monitoring and analysis of markets and policies to facilitate adaptation when the unpredictable happens [87, P82]. The global shift to the use of energy markets to price energy during the 1970s was a significant advance in the adaptive capacity of the energy system as it can provide a fast variable response to an underlying structural supply-demand imbalance. The implementation of energy security measures have therefore adhered to the ecological understanding of resilience measurement; that the slow variables that underpin the function and performance of the system [8], in this case diversity, efficiency and spare capacity, enhance adaptive capacity. The energy market reveals the dynamics of the underlying adaptive capacity of the system, with high prices (the fast variable response) indicating a lack of adaptive capacity but providing a mechanism for assisting the system to respond to perturbations. There has however been little statistical analysis of the selection of, and coefficients for, those protective factors in a basket of energy security measures.

Watts, Strogatz, Barabasi and Albert's measurement of network structure all highlight the spectrum of different system structures that yield different combinations of strengths and weaknesses, and thus the potential for different outcomes. Where efficiency of operation is the critical outcome, then the structure of the organisation will be based on efficiency only. By contrast, where robustness of organisation is required then the structure of the organisation needs to show diversity and redundancy to enhance robustness. In most cases, it will be a matter of balance. A network that displays inherent redundancy by a greater number of connections and a network that has a diversity of paths provide greater adaptive capacity, making networks with greater connectivity more resilient to surprise attacks. The understanding of structure that the measurement of network provides represents a subset 
of resilience, a metric for system performance, rather than an equivalent construct of system adaptive capacity.

Measurement of resilience throughout all the research implies measurement of adaptive capacity, and the concepts of diversity, redundancy, system structure and monitoring are implied in many of the research findings highlighting their key involvement in advancing adaptive capacity and survival.

\section{Adaptive capacity and energy system resilience}

\subsection{A review of the nature of adaptive capacity}

Simon's analysis of systems and their ability to adapt to their environments starts with comparing adaptation to the property of homeostasis or, in biological terms, the ability of an organism to regulate its internal processes, generally by feedback mechanisms, in response to external changes. He argues that if the inner system is correctly designed it will be adapted to the external environment through a feedback system. However, the difficulty in designing inner systems resides in predicting how the components of the system will behave in uncertain future external environments, such that in general, new systems are developed, tested to understand their reaction to changes in the external environment, and then adjusted as their responses and adaptive qualities are better understood [88].

Simon highlights the importance of this process of small steps taken by adaptive systems in response to uncertain environments throughout his discussion of rational behaviour. Darwinian evolution provides plenty of evidence of a process of small, incremental adjustment to change, as do artificial systems like the internet. Thus adaptation is about adequacy rather than optimality because optimality requires the impossible assumption of complete information. For this reason, experience and judgement play a vital role in how organisations develop frameworks to guide adaptation [88].

Adaptive capacity in Simon's view, as in strategic response in war, is about opportunistic response to surprise. Equally important, it is about a capacity for alternatives. This ability to respond to surprise is what has characterised much of the research into psychological resilience, suggesting that coping capacity is analogous to adaptive capacity.

Ecologists state that homeostasis is not at the heart of ecosystem equilibrium [89, P26]. They hold that novelty and innovation are the key elements for adaptation because they provide rich opportunities for experimentation that leads to high levels of diversity within and between ecological systems [90]. They cite the major innovations in the history of life on earth such as the spread of metabolic activities, photosynthesis and multi-cellular organisms as the outcome from an "evolutionary triad of challenge, potential and opportunity" [90, P32]. However, would it not be safe to conclude from the Holling view, that over the millennia, the challenges have been created by the variability of the external 
environment, and the potential facilitated by self-organisation or homeostasis for opportunism and survival?

It is perhaps a matter of terminology. The Holling school claims that adaptive capacity requires a balance between stabilizing and destabilizing forces that test the degree and intensity of internal controls and the degree and influence of external variability [89]. This would support the Simon view of adaptive capacity as a homeostatic capacity within the system to respond to the episodic forces external to the system. This brings the discussion back to what it is that facilitates the internal flexibility of the internal controls to adapt to the episodic change.

For a harmonised view of what facilitates the flexibility of internal controls to adapt, a return to the Holling school's theory of change, the adaptive cycle, which requires three properties to shape response to future shocks may yield insights. The first property is "potential for change" which although specific to each situation is represented by "capital" accumulated as a response to a phase of growth. Accumulated capital could in effect be defined as spare capacity or redundancy. The second property is "connectedness" which is the strength of the internal connections that mediate and regulate influences on the system. High connectedness dampens response to external fluctuations. This system integrity could also be defined as efficiency. The third property is "resilience" [89] but in many of the Holling school discussions there are circular references between adaptive capacity and resilience; that is, the property of resilience is required for adaptive capacity $[89$, P33], but adaptive capacity is required for resilience [8, P766]. In the discussions about adaptive cycle, resilience is defined as providing a shifting balance between vulnerability and persistence [89]. But to shift between these states requires alternatives or a diversity of options. Thus the properties required for adaptation could be represented by redundancy, efficiency and diversity.

To provide a more practical demonstration of the synergies between the views discussed, it is useful to turn to Carpenter et al's discussion of resilience measurement. They propose that the underlying structure of the system will determine how the system responds to a disturbance; that slow-moving variables define structure and fast-moving variables reveal the dynamics of the structure [8]. A slow-moving variable often cited as an example is soil phosphate, which serves as a field metric of water quality in lakes. The problem with using a slow-moving variable to define the structure of the system is that it tells us very little about the system structure and its adaptive capacity. A clearer picture of the system's ability to adapt to a stochastic shock would be to define its structure according to its selforganisation. If adaptive capacity can be represented by: spare capacity (in this case, the head room available for additional loads of phosphorus that can be accommodated without significant deterioration in water quality); efficiency (the rate at which phosphorus can be dispersed); and diversity (the alternatives available to disperse phosphorus), these metrics 
would provide indicators of the capacity of the system to respond to surprising events, and guidance for management intervention as required.

Resilience then is the state or quality of a system's adaptive capacity. A system that has a high level of adaptive capacity is resilient, whereas a system that has a low level of adaptive capacity is vulnerable. The identification of different phases in the adaptive cycle from exploitation to consolidation, destruction and reorganisation [89] do not tell us about the adaptive capacity of the system, but rather where it is in an adaptive cycle. Understanding the levels of redundancy, efficiency and diversity of the system required to facilitate adaptation in response to disturbance at each stage in the adaptive cycle would be a better indicator of the resilience or vulnerability of the system.

"Resilience, in short, is largely about learning how to change in order not to be changed. Certainty is impossible. The point is to build systems that will be safe when they fail, not to try to build fail-safe systems." Brian Walker on http://energlobe.eu/society/what-isresilience-useful-concept-or-fleeting-buzzword

\subsection{Key components of adaptive capacity}

Discussion about resilience and energy security suggest that adaptive capacity can be represented by measures of spare capacity, efficiency and diversity because these characteristics provide indicators of capacity to respond opportunistically to change.

\subsubsection{Diversity}

There has been disagreement amongst ecologists about the benefits of diversity for stability. MacArthur used a simple food web model to illustrate the effect of diversity on energy flow [81]. His understanding of stability suggested that the greater opportunity for alternatives, the greater would be the stability of the food-web. He proposed the most appropriate stability function to be:

$$
S=-\sum p_{i} \log p_{i} \quad \text { Equation } 1
$$

where $S$ is the stability of the food web, and $p_{i}$ is probability that energy will pass to any predator, which was identical in form to entropy as devised by Maxwell-Boltzmann and uncertainty as devised by Shannon-Weaver. He drew the conclusion that with increased stability comes restricted diet through competition for resources, but that restricted diet promoted efficiency. Thus efficiency and stability were requirements for survival under natural selection [81].

The discussion around the merits of diversity for stability was upended by May's mathematical analysis of complex systems. Complexity was measured by the number and nature of the individual links in the food web and stability was measured by the tendency for population perturbations to diminish and return to some persistent configuration defined by a deterministic equilibrium point. He found that increasing complexity would diminish stability at higher levels of complexity [91] 
McNaughton found plenty of evidence to point to the diversity-stability relationship and concluded that confusion around the apparent contradiction between the mathematical models of May and experience in the field had something to do with compensatory activity between co-occurring species but more to do with the lack of appropriate empirical data than confounding evidence [82].

Tilman, in his analysis of the relationship between species richness and year-to-year variability in species and community biomass and drought resistance, found that more diverse grassland plots were more stable with respect to a drought but also with respect to normal yearly climate variation [23]. Although, at the detailed level, he found that the biomasses of individual species tended to show greater year-on-year variability in species rich plots, which tended to support May's predictions. Like McNaughton, Tilman's explanation of the apparent anomaly was "interspecific competition" which magnifies the effects of a disturbance on the production of individual species causing some species to flourish and others to flounder, with the species acting in concert to stabilise the community. May too acknowledged this inconsistency which he detailed in the "Afterthoughts" to his book [92, P231-232]:

, where if we concentrate on any one particular species our impression will be one of flux and hazard, but if we concentrate on total community properties (such as biomass in a given trophic level) our impression will be of pattern and steadiness.

Ulanowicz concluded that May's finding of instability from complexity was as a result of the system being over-connected [29]. He suggested that May did not include the stabilising influence of reserve capacity to keep the system from approaching its maximum.

The apparent contradiction between the mathematical model as formulated by May and empirical findings as reported by field studies [23], [21] and [22], tended to hamper the inclusion of diversity as a fundamental characteristic of ecological stability or resilience. Arguments as to the evidence, or lack of, from the empirical findings centred on the structure of the experiments, the choice of variables, comparisons across different temporal and spatial scales and the interpretation of the results [24].

Notwithstanding the contradictions discussed by ecologists, other disciplines' measurement of preparedness for the unexpected show evidence of implicitly deploying diversification to respond to uncertainty and shock, as summarised here:

- Energy policy has gravitated towards diversification as a requirement for energy security. Bodies like the Organisation for Economic Cooperation and Development (OECD) and IEA include diversity of fuel supplier as important to secure energy supplies as a result of the hard experience gained during the 1970s when global supplies of oil pivoted on supplies from countries with divergent interests from consuming countries. 
- Psychological resilience research also noted the benefit of education, and the benefit of social relationships $[34,38]$, in providing people with alternatives for responding to hardship.

- Investment systems developed to manage risk quantified the benefits of diversification in using portfolio theory [45].

- The insurance industry, the most fundamental of risk management systems, has grown from risk sharing which implicitly assumes diversity where the risk averse help to fund risk seekers, and the fortunate help to fund the unfortunate.

\subsubsection{Redundancy, or spare capacity}

The concept of redundancy, although strongly associated with biodiversity, is generally bundled up as a benefit associated with biodiversity. Referred to as 'species richness', Tilman found that species richness increases the efficiency and stability of some ecosystem functions but decreased population stability [23].

Discussions of the ecological similarities shown by dissimilar species, have led to the postulate that species are organised into functional groups determined by ecological processes. The ecological functions of species compensate for and complement other species in their functional group to ensure functional overlap and thus enable an ecosystem to persist [7]. Some field studies but not all show that ecological processes stabilise with species richness. However, the studies also suggest that a diversity of functional groups is a larger driver of stability, than is redundancy. They conclude that "since no species are identical, redundancy does not reside in groups of species, but rather it emerges from interactions of species. Therefore it is not possible to substitute species for one another; rather there are many possible combinations and organisations of species that can produce similar ecological functions" [7, P10]

There is also much discussion about biodiversity in terms of an insurance benefit which theoretically implies that species richness provides a buffer, that is a reduction in the temporal variance of productivity, and enhanced production in the form of an increase in the temporal mean of productivity [93].

Ulanowicz develops the concept of redundancy as the product of autocatalysis, which is analogous to adaptive capacity [26]. In his view, system ascendancy, that is the organisation and size of the system, will increase as a result of autocatalytic response to random small shocks. The development of this 'system overhead' effectively serves as a mechanism to maintain system integrity and to provide 'sustenance for the future'. He finds that accumulation, or redundancy, is the cost of persistence.

Taking a slightly different approach Zolly and Healy suggest that 'firebreaks', or the capacity to island sub-systems within networks, need to be added to system structure to halt the spread of attack or failure [47]. Aligned to but different from the concept of redundancy, 'firebreaks' are an important component of any system which is designed to be efficient in 
distribution. It suggests a more targeted approach to redundancy, where weaknesses in the structure are identified and sensors set to trigger alerts when thresholds are breached. It is reminiscent of the concept of engineered resilience or to be "robust but fragile" [47].

All disciplines' discussion about being prepared for the unexpected, whilst using different terminology, imply that spare capacity is an important component of stability and persistence. Energy policy, rolled out after the 1973 oil embargo, requires that strategic reserves of oil are held to provide a buffer against cyclical or political supply shocks. Network theory suggests that networks that have redundant interconnections are more robust complex systems [79]. Longitudinal studies to determine the protective factors necessary for psychological resilience, find that work outside the home when people are teenagers and education are indicators of positive outcomes [34], which would imply that employment and especially higher paid employment as a result of education provide a buffer against downward spirals when adversity strikes. Resilience Engineering refers specifically to buffering capacity as a required property to enable a system to absorb and adapt to exogenous change to maintain a dynamically stable complex system [94].

\subsubsection{Efficiency and system structure}

Whilst social constructs like economics use models that are predicated on the efficiency of resource allocation, Ulanowicz using information theory has discussed the requirement for efficiency and order within an ecosystem to enable growth [29]. However, for systems to survive the unexpected, the order within the system needs to be balanced with disorder.

Small World Networks, that is networks that are characterized by short path lengths and a few highly connected nodes, are efficient and effective at reducing overhead and resource use. The structure of the flow of components through the system therefore influences both the input and outputs of the system. As noted in the discussion about network attack tolerance, a system geared mainly to efficiency will be vulnerable to large, surprise events. For this reason, efficiency needs to be balanced with redundancy and diversity to decrease risk and increase adaptive capacity.

Energy security also promotes the need for energy systems to be efficient in their resource use using a combination of regulation and competition to facilitate efficiencies. In the 1970s as prices rose due to constrained oil supplies, the US government regulated to ensure that efficiency standards reduced consumption. Also, a liquid market evolved to respond to oil shortages, which drove prices up, leading to increased efficiency.

Resilience Engineering proposes that complex systems need to operate under conditions of thoroughness but also efficiency [43]. Efficiency however is the hallmark of all economic analyses, and thus can be considered to be a fundamental expectation of effective system operation.

Thus, the organisational structure of the system plays a significant role in its effective operation. Highly structured organisation can lead to greater specialisation and hence 
efficiency, whereas less structured organisation implies less efficiency but greater freedom in response to change and protection against failure.

\subsection{Adaptive capacity and energy security}

The oil crises of the 1970s and early 1980s saw energy prices escalate. In terms of the discussion above, the rise in energy prices (as the fast variables of the energy system) reflected the lack of adaptive capacity in energy systems. Global energy consumption, but especially in some states in the US and Japan, had concentrated around oil showing little diversification in their energy systems. The stand-off between OPEC and consuming nations was facilitated by the Texas Railroad Commission's decision in 1971 to allow full oil production in the US eroding its buffer or capacity to respond to unexpected change [1]. After the oil crises, energy policy in the United States, Japan and Europe included action on diversification of fuel source, efficiency of energy use and spare capacity in energy resources to be prepared for future fuel shocks. Whilst there was debate on the calculation of the optimum size of reserve requirements [53], there was little discussion on attempting to calculate adequate levels of diversification in fuel type and improvement in energy efficiency.

Not discussed was the role played by hydroelectricity in mitigating against the impact of energy price rises between 1973 and 1982. Figure 1 (attached) shows aggregated prices for electricity to industrial customers in states in the US with systems dominated by particular fuel types (dominated is assessed to be $75 \%$ or more of generation from any particular fuel type). States with high levels of hydro-electricity enjoyed low electricity prices and smaller increases in electricity prices over the period of the 1970s oil crises. This illustrates the benefits associated with including renewable energy in electricity portfolios which reduce risks associated with global fossil fuel price volatility.

The collapse of oil prices in the mid-1980s allowed complacency to return. Attention focussed again on energy security only when oil prices started rising in the mid-2000s as China's escalating consumption uncovered the innate lack of adaptive capacity in the global energy system. Unconventional gas production and renewable forms of electricity generation have helped diversify stationary energy promising greater levels of energy security and resilience $[59,64,85,86]$. However, little has been done to quantify the benefits or measure adaptive capacity in liquid fuels. For energy systems to be resilient and secure, greater analysis is required to determine adequate levels of adaptive capacity in the form of diversification, spare capacity and energy efficiency across all fuel types.

\section{Conclusion}

If resilience is defined as the state or quality of a system's capacity to cope with the unexpected, measuring resilience is synonymous with measuring adaptive capacity. Whilst multiple mathematical models have been proposed to measure response to change in ecosystems and the welfare consequences of energy insecurity, the statistical methods 
employed in the analysis of psychological resilience and risk management have provided a more pragmatic framework for understanding the protective and risk factors most significant when facing the unexpected. In recognition of the greater success shown in measuring risk in portfolio management and insurance, and the identification of protective factors for positive psychological outcomes, resilience needs to be assessed around the factors that are most important in being able to adapt to the unexpected.

Resilience in energy systems is perhaps the most compelling of challenges facing global welfare. With energy systems dependent on fossil fuels that emit high levels of carbon dioxide leading to the accumulation of greenhouse gases and climate change, it is imperative that the energy systems are prepared for significant levels of change to reduce emissions of carbon dioxide. The proposal here is that the extent of protective factors associated with adaptive capacity for energy systems should be identified using statistical analysis, such that investment in national systems can be directed towards ensuring that energy systems become resilient, and in so doing, protect or even enhance economic welfare. 


\section{References}

[1] Yergin D. The prize: the epic quest for oil, money, and power. New York: Simon and Schuster; 1991.

[2] Jones DW, Leiby PN, Paik IK. Oil Price Shocks and the Macroeconomy: What Has Been Learned Since 1996. The Energy Journal. 2004;25:1-32.

[3] Hamilton JD. Nonlinearities and the macroeconomic effects of oil prices. Macroeconomic Dynamics. 2011;15:364-78.

[4] Pimm SL. The complexity and stability of ecosystems. Nature. 1984;307:321-6.

[5] Holling CS. Resilience and Stability of Ecological Systems. Annual Review of Ecology and Systematics. 1973;4:1-23.

[6] Gunderson LH, Holling CS. Panarchy: Understanding transformations in human and natural systems. Washington, DC: Island Press; 2002.

[7] Peterson G, Allen CR, Holling CS. Ecological Resilience, Biodiversity, and Scale. Ecosystems. 1998;1:6-18.

[8] Carpenter S, Walker B, Anderies JM, Abel N. From Metaphor to Measurement: Resilience of What to What? Ecosystems. 2001;4:765-81.

[9] Holling CS, Schindler DW, Walker BW, Roughgarden J. Biodiversity in the functioning of ecosystems: an ecological synthesis. In: Perrings C, Maler K-G, Folke C, Holling CS, Jansson BO, editors. Biodiversity Loss: Economic and Ecological Issues: Cambridge University Press; 1995.

[10] Walker B. Conserving Biological Diversity through Ecosystem Resilience. Conservation Biology. 1995;9:747-52.

[11] Lewontin RC. The meaning of stability. Diversity and stability in ecological systems. Upton, New York: Brookhaven National Laboratory, Clearinghouse for Federal Scientific and Technical Information, Springfield, Virginia; 1969.

[12] Rosenzweig ML, MacArthur RH. Graphical Representation and Stability Conditions of Predator-Prey Interactions. The American Naturalist. 1963;97:209-23.

[13] Rosenzweig ML. Paradox of Enrichment: Destabilization of Exploitation Ecosystems in Ecological Time. Science. 1971;171:385-7.

[14] Perrings C. Resilience in the Dynamics of Economy-Environment Systems. Environ Resource Econ. 1998;11:503-20.

[15] Wootton JT. Prediction in complex communities: Analysis of empirically derived markov models. Ecology. 2001;82:580-98.

[16] Pawlowski CW, McCord C. A Markov model for assessing ecological stability properties. Ecological Modelling. 2009;220:86-95.

[17] Berkes F, Folke C, Colding J. Linking social and ecological systems: management practices and social mechanisms for building resilience. Cambridge, UK: Cambridge University Press; 1998.

[18] Carpenter S, Brock W, Hanson P. Ecological and social dynamics in simple models of ecosystem management. Ecology and Society. 1999;3.

[19] Janssen MA, Walker BH, Langridge J, Abel N. An adaptive agent model for analysing coevolution of management and policies in a complex rangeland system. Ecological Modelling. 2000;131:249-68. 
[20] Dixon JA. Economic analysis of environmental impacts London: Earthscan in association with the Asian Development Bank and the World Bank,; 1994.

[21] McGrady-Steed J, Harris PM, Morin PJ. Biodiversity regulates ecosystem predictability. Nature. 1997;390:162-5.

[22] Naeem S, Li S. Biodiversity enhances ecosystem reliability. Nature. 1997;390:507-9.

[23] Tilman D. Biodiversity: Population Versus Ecosystem Stability. Ecology. 1996;77:350-63.

[24] Loreau M. Biodiversity and Ecosystem Functioning: Recent Theoretical Advances. Oikos. 2000;91:3-17.

[25] Slobodkin LB. The strategy of evolution. American Scientist. 1964;52:342-57.

[26] Ulanowicz RE. Ascendancy: A measure of ecosystem performance. In: Jorgensen SE, Müller F, editors. Handbook of Ecosystem Theories and Management. Boca Raton: Lewis Publishers; 2000. p. 303-15.

[27] Li Y, Yang ZF. Quantifying the sustainability of water use systems: Calculating the balance between network efficiency and resilience. Ecological Modelling. 2011;222:1771-80. [28] Ulanowicz RE. Quantitative methods for ecological network analysis. Computational Biology and Chemistry. 2004;28:321-39.

[29] Ulanowicz RE, Goerner SJ, Lietaer B, Gomez R. Quantifying sustainability: Resilience, efficiency and the return of information theory. Ecological Complexity. 2009;6:27-36. [30] Redl F. Adolescents - Just How Do They React? In: Caplan G, Lebovici S, editors. Adolescence: Psycholsocial Perspectives. New York: Basic Books; 1969. p. 79-99.

[31] Murphy LB. Further reflections on resilience. In: Anthony EJ, Cohler BJ, editors. The Invulnerable Child. New York: The Guilford Press; 1987. p. 84-105.

[32] Anthony EJ. Risk, Vulnerability, and Resilience: An Overview. In: Anthony EJ, Cohler BJ, editors. The Invulnerable Child. New York: The Guilford Press; 1987.

[33] Cohler BJ. Adversity, Resilience, and the Study of Lives. In: Anthony EJ, Cohler BJ, editors. The Invulnerable Child. New York: The Guilford Press; 1987. p. 363-409.

[34] Felsman JK, Vaillant GE. Resilient Children as Adults: A 40 Year Study. In: Anthony EJ, Cohler BJ, editors. The Invulnerable Child. New York: The Guilford Press; 1987. p. 289-314.

[35] Masten AS. Ordinary magic: Resilience processes in development. American Psychologist. 2001;56:227-38.

[36] Ungar M. The social ecology of resilience: a handbook of theory and practice. New York: Springer New York; 2012.

[37] Luthar SS. Resilience in Development: A Synthesis of Research across Five Decades. In: Cicchetti D, Cohen DJ, editors. Developmental Psychopathology: Risk, Disorder and Adaptation. Second ed. Hoboken, New Jersey: John Wiley \& Sons; 2006.

[38] Werner EE, Smith RS. Journeys from Childhood to Midlife: Risk, Resilience and Recovery. New York: Cornell University; 2001.

[39] McConnell D, Savage A, Breitkreuz R. Resilience in families raising children with disabilities and behavior problems. Research in Developmental Disabilities. 2014;35:833-48. [40] Knight FH. Risk, uncertainty and profit. Midway Reprint ed. Chicago: University of Chicago Press; 1985.

[41] Adams J. Risk. London [England] : Bristol, PA :: UCL Press; 1995.

[42] Bernstein PL. Against the gods : the remarkable story of risk. New York :: John Wiley \& Sons; 1996.

[43] Hollnagel E, Woods DD, Leveson NG. Resilience engineering: concepts and precepts. Burlington, VT: Ashgate; 2006. 
[44] Tversky A, Kahneman D. Rational Choice and the Framing of Decisions. The Journal of Business. 1986;59:S251-S78.

[45] Markowitz H. Portfolio Selection. The Journal of Finance. 1952;7:77-91.

[46] Dobbins R, Witt SF, Fielding J. Portfolio theory and investment management. Oxford: Blackwell Business; 1994.

[47] Zolli A, Healy AM. Resilience: why things bounce back. New York: Simon \& Schuster Paperbacks; 2013.

[48] Grubb M, Butler L, Twomey P. Diversity and security in UK electricity generation: The influence of low-carbon objectives. Energy Policy. 2006;34:4050-62.

[49] Winzer C. Conceptualizing energy security. Energy Policy. 2012;46:36-48.

[50] von Hippel D, Suzuki T, Williams JH, Savage T, Hayes P. Energy security and sustainability in Northeast Asia. Energy Policy. 2011;39:6719-30.

[51] Kruyt B, van Vuuren DP, de Vries HJM, Groenenberg H. Indicators for energy security. Energy Policy. 2009;37:2166-81.

[52] Lefèvre N. Measuring the energy security implications of fossil fuel resource concentration. Energy Policy. 2010;38:1635-44.

[53] Bohi DR, Toman MA, Walls MA. The economics of energy security. Boston :: Kluwer Academic Publishers; 1996.

[54] Vivoda V. Evaluating energy security in the Asia-Pacific region: A novel methodological approach. Energy Policy. 2010;38:5258-63.

[55] Sovacool BK, Mukherjee I. Conceptualizing and measuring energy security: A synthesized approach. Energy. 2011;36:5343-55.

[56] US Chamber of Commerce. Assessing America's vulnerabilities in a global energy market. Washington, DC: Institute for 20th Century Energy,; 2013.

[57] Stirling A. Diversity and ignorance in electricity supply investment: Addressing the solution rather than the problem. Energy Policy. 1994;22:195-216.

[58] Stirling A. Multicriteria diversity analysis: A novel heuristic framework for appraising energy portfolios. Energy Policy. 2010;38:1622-34.

[59] Chuang MC, Ma HW. Energy security and improvements in the function of diversity indices-Taiwan energy supply structure case study. Renewable and Sustainable Energy Reviews. 2013;24:9-20.

[60] Bhattacharyya SC. Fossil-fuel dependence and vulnerability of electricity generation: Case of selected European countries. Energy Policy. 2009;37:2411-20.

[61] IEA. Measuring Short-Term Energy Security. Paris: International Energy Agency; 2011.

[62] Awerbuch S. Getting it right: The real cost impacts of a renewables portfolio standard. Public Utilities Fortnightly. 2000;138:44-55.

[63] Awerbuch S, Berger M. Applying Portfolio Theory to EU Electricity Planning and Policy Making. IEA/EET Working Paper. Paris: IEA; 2003.

[64] Escribano Francés G, Marín-Quemada JM, San Martín González E. RES and risk:

Renewable energy's contribution to energy security. A portfolio-based approach. Renewable and Sustainable Energy Reviews. 2013;26:549-59.

[65] Gately D. A Ten-Year Retrospective: OPEC and the World Oil Market. Journal of Economic Literature. 1984;22:1100-14.

[66] Adelman MA. Scarcity and World Oil Prices. The Review of Economics and Statistics. 1986;68:387-97.

[67] Adelman MA. The Clumsy Cartel. The Energy Journal. 1980;1:43-53. 
[68] Huntington HG. Energy disruptions, interfirm price effects and the aggregate economy. Energy Economics. 2003;25:119-36.

[69] Brown SPA, Huntington HG. Assessing the U.S. oil security premium. Energy Economics. 2013;38:118-27.

[70] Ministry of Defence. British Defence Doctrine. 4th ed. Swindon, UK2011.

[71] Wilson RJ. Introduction to graph theory. London: Longman; 1975.

[72] Hall CS, Klitgaard K. Energy and Wealth Production: An Historical Perspective. Energy and the Wealth of Nations: Springer New York; 2012. p. 41-69.

[73] Tainter JA. The collapse of complex societies. Cambridge ; Melbourne :: Cambridge University Press; 1988.

[74] Travers J, Milgram S. An Experimental Study of the Small World Problem. Sociometry. 1969;32:425-43.

[75] Milgram S. The Small World Problem. Psychology Today. 1967;1:61-7.

[76] Winfree A. The Geometry of Biological Time. New York: Springer; 1980.

[77] Braiman Y, Lindner JF, Ditto WL. Taming spatiotemporal chaos with disorder. Nature. 1995.

[78] Watts DJ, Strogatz SH. Collective dynamics of 'small-world' networks. Nature. 1998;393:440-2.

[79] Albert R, Hawoong J, Barabasi A-L. Error and attack tolerance of complex networks. Nature. 2000;406:378-82.

[80] Pimm SL. The balance of nature? : ecological issues in the conservation of species and communities. Chicago :: University of Chicago Press; 1991.

[81] MacArthur R. Fluctuations of Animal Populations and a Measure of Community Stability. Ecology. 1955;36:533-6.

[82] McNaughton SJ. Diversity and Stability of Ecological Communities: A Comment on the Role of Empiricism in Ecology. The American Naturalist. 1977;111:515-25.

[83] Gillham J, Hamilton J, Freres D, Patton K, Gallop R. Preventing Depression Among Early Adolescents in the Primary Care Setting: A Randomized Controlled Study of the Penn Resiliency Program. J Abnorm Child Psychol. 2006;34:195-211.

[84] Reivich KJ, Seligman MEP, McBride S. Master resilience training in the U.S. Army. American Psychologist. 2011;66:25-34.

[85] Valentine SV. Emerging symbiosis: Renewable energy and energy security. Renewable and Sustainable Energy Reviews. 2011;15:4572-8.

[86] Hinrichs-Rahlwes R. Renewable energy: Paving the way towards sustainable energy security: Lessons learnt from Germany. Renewable Energy. 2013;49:10-4.

[87] Yergin D. Ensuring Energy Security. Foreign Affairs. 2006;85:69-82.

[88] Simon HA. The sciences of the artificial. 2d ed., rev. and enl. ed. Cambridge, Mass. ::

MIT Press; 1981.

[89] Holling CS, Gunderson LH. Resilience and Adaptive Cycles. In: Gunderson LH, Holling CS, editors. Panarchy: Understanding Transformations in human and natural systems.

Washington, DC: Island Press; 2002. p. 25-62.

[90] Holling CS, Allen C, R. . Novelty, Adaptive Capacity, and Resilience. Ecology and society. 2010;15:24-.

[91] May RM. Will a Large Complex System be Stable? Nature. 1972;238:413-4.

[92] May RM. Stability and complexity in Model Ecosystems. Princeton, New Jersey:

Princeton University Press; 1974. 
[93] Yachi S, Loreau M. Biodiversity and ecosystem productivity in a fluctuating environment: The insurance hypothesis. Proceedings of the National Academy of Sciences. 1999;96:1463-8.

[94] Woods DD. Essential Characteristics of Resilience. In: Hollnagel E, Woods DD, Leveson NG, editors. Resilience engineering: concepts and precepts. Burlington, VT: Ashgate; 2006. p. 21-33. 